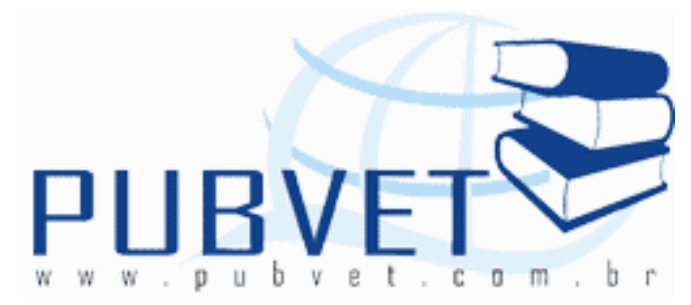

PUBVET, Publicações em Medicina Veterinária e Zootecnia.

\title{
Ácidos graxos poli-insaturados de cadeia longa na alimentação de não ruminantes
}

\author{
Juliana Klug Nunes ${ }^{1}$, Verônica Lisboa Santos ${ }^{2}$, Fernando Rutz ${ }^{3}$, Marcos \\ Antonio Anciuti $^{4}$
}

${ }^{1}$ Médica Veterinária, D.Sc., Universidade Federal de Pelotas (UFPel) Campus Universitário s/n, 96010-900, Capão do Leão/RS, Brasil.

${ }^{2}$ Engenheira Agrônoma, M.Sc., UFPel.

${ }^{3}$ Médico Veterinário, Ph.D., Prof. UFPel.

${ }^{4}$ Médico Veterinário, D.Sc. Prof. Instituto Federal Sul-Rio-grandense, Campus Visconde da Graça (CaVG), Pelotas/RS, Brasil.

\section{Resumo}

Objetivou-se compilar informações sobre suplementação de ácidos graxos poli-insaturados de cadeia longa (PUFAS) das séries ômega 3 (eicosapentanoico - EPA) e 6 (docosahexanoico - DHA) na dieta de animais não ruminantes e benefícios dessa à saúde animal e humana. O tipo de gordura presente na dieta dos animais não ruminantes influencia na composição de ácidos graxos dos lipídios de depósito o que beneficia os consumidores das carnes de aves e suínos, pois poderão contar com fontes de PUFAS das séries ômega 3 e 6 para auxiliar na manutenção da saúde, principalmente a do coração. Em cães e gatos alimentados com óleos vegetais, fonte rica em PUFAS ômega 6, e óleo de peixe, fonte, principalmente, de PUFAS ômega 3 , os efeitos na redução de danos ao 
miocárdio, o efeito anti-inflamatório e o auxílio no tratamento de neoplasia foram comprovados. Pelos benefícios que proporciona, a indústria de alimentos tende a investir na produção de alimentos funcionais que contenham EPA e/ou DHA.

Palavras-chave: alimentação, aves, cães, gatos, ômega 3, ômega 6, suínos.

\section{Polyunsaturated fatty acid to long chain feeding non-ruminant}

\section{Summary}

The objective was to compile information on the supplementation of fatty acids polyunsaturated long chain (PUFAs) series omega 3 (eicosapentaenoic - EPA) and 6 (docosahexaenoic acid - DHA) in diets for non-ruminants and benefits of this to animal and human health. The type of fat in the diet of non-ruminant animals influences the fatty acid composition of lipids deposit which benefits consumers of poultry and pigs, they may rely on sources of PUFAS omega 3 and 6 to assist in maintaining health, especially the heart. In dogs and cats fed with vegetable oils rich source of omega- 6 PUFAs, and fish oil, a source primarily of omega-3 PUFAs, effects on reducing myocardial damage, the anti-inflammatory effect and aid in the treatment of neoplasia been proven. The benefits it provides, the food industry tends to invest in the production of functional foods containing EPA and/or DHA.

Keywords: feeding, birds, dogs, cats, omega 3, omega 6, pigs.

\section{Introdução}

O colesterol é importante para manter a saúde e diversas funções no organismo animal, logo ele é exigido por todos os tecidos e células vivas do corpo. O colesterol é componente da célula, atua na síntese de ácidos biliares que participam da emulsificação, digestão e absorção de lipídios e vitaminas lipossolúveis, participa da síntese de hormônios esteroides, 
vitamina $E$, e é componente da pele. Portanto, problemas no seu metabolismo podem aumentar a sua concentração no sangue, acarretando o aparecimento de doenças coronarianas, como arterosclerose, causando hipertensão arterial, problemas de diabete mellitus e formação de cálculos biliares (LUDKE \& LOPEZ, 1999).

Entretanto por problemas de saúde e pela busca de uma alimentação saudável, os consumidores evitam o consumo de alimentos nutritivos como, por exemplo, a carne suína que não apresenta teor de colesterol maior do que o da carne bovina ou de frango. É importante enfatizar que a causa do aumento do nível de colesterol sanguíneo, em humanos, é multifatorial, sendo um dos problemas relacionados à quantidade e o tipo de gordura, seja ela monoinsaturada, poli-insaturada ou saturada, que está presente na dieta e não diretamente a carne (MARTIN et al., 2006). A maior parte da gordura do suíno, cerca de $70 \%$ está localizada abaixo da pele e não entre as fibras musculares o que seria o maior problema (SILVA, 1995).

Em geral, os ácidos graxos saturados aumentam e os poli-insaturados diminuem a concentração de colesterol no plasma de humanos, já o ácido graxo monoinsaturado (ácido oleico) e o ácido esteárico saturado permanecem neutros (NORUM, 1992).

Nesse contexto, a indústria de alimentos está investindo na produção de produtos funcionais (MOURÃO et al., 2005) que é definido pelo Agência Nacional de Vigilância Sanitária como nutriente ou não nutriente que desempenha papel metabólico ou fisiológico contribuindo para o crescimento, desenvolvimento, maturação e outras funções normais do organismo humano (ANVISA, 1999).

\section{Ácidos graxos poli-insaturados ômega 3 e 6}

Para humanos, uma dieta saudável apresenta ácidos graxos mono e poli-insaturados, em detrimento dos saturados e dos poli-insaturados do tipo trans (RAMOS \& RAMOS, 2005). Existem basicamente três ácidos graxos 
poli-insaturados (PUFAS) ômega 3 - o ácido alfa-linolênico $\left(C_{18: 3 n-3}\right)$ que é encontrado em folhas de plantas e sementes de vegetais, como o linho e a colza, o ácido eicosapentaenoico (EPA, $C_{20: 5 n-3}$ ) e o docosahexanoico (DHA, $\mathrm{C}_{22: 6 n-3)}$ que estão presentes nos óleos de peixes de águas frias e profundas, como sardinha, salmão, atum, cavala, arenque e truta, plâncton, vegetais de folhas verdes escuras - espinafre, brócolis, couve - nozes, óleos de canola, e linhaça (LARSSON et al., 2004), e podem, também, ser obtidos pelo homem e pelos animais, através da dessaturação e alongamento da cadeia do ácido alfa linolênico, mas a taxa de conversão é muito baixa e diminuiu ainda mais com o aumento da quantidade do ácido linoleico, pois no organismo dos mamíferos os ácidos linoleico e o alfa-linolênico competem pela enzima delta-6 dessaturase (TEIXEIRA, 2004).

Em felinos, por exemplo, nenhuma ou muito baixa eficiência da enzima delta-6 dessaturase foi demonstrada (MORRIS, 2004). Os ácidos graxos de cadeia longa com duas ou mais insaturações não são sintetizados por mamíferos, se tornando essenciais para estas espécies (TREVIZAN \& KESSLER, 2009). Logo, a quantidade de ômega 3 e 6 encontrados nas células depende da sua quantidade na dieta (MARTIN et al., 2006).

Os peixes obtêm EPA e DHA ao consumirem o fitoplâcton e o zooplâncton e a concentração destes ácidos graxos poli-insaturados (Tabela 1) varia com a espécie de peixe, total de gordura corporal, localização geográfica e águas que habitam (BERQUIN et al., 2008).

Tabela 1. Concentração de ácidos graxos ômega 3 em peixes marinhos

\begin{tabular}{ll}
\hline Peixe & Ácido graxo ômega 3 \\
\hline Cavala & $1,8-5,1$ \\
Arenque & $1,2-3,1$ \\
Sardinha & 1,7 \\
Salmão & $1,0-1,4$ \\
Atum & $0,5-1,6$ \\
Truta & $0,5-1,6$
\end{tabular}

Fonte: SCHMIDIT et al. (1994). 
Em relação aos ácidos graxos ômega 6, os ácidos graxos ômega 3 são mais eficientes em reduzir a concentração de triacilglicerois no plasma, isso porque os óleos de peixes inibem a síntese e a secreção de triacilglicerois, inibem a síntese e aumentam a oxidação do ácido graxo, diminuem a atividade de enzimas responsáveis para esterificação de ácido graxo e mudam a relação dos ésteres de ácidos graxos formados (CONIGLIO, 1992). Além disso, as gorduras poli-insaturadas são rapidamente diluídas, provavelmente, devido ao aumento da susceptibilidade dos quilomicrons poli-insaturados à lipase lipoproteica (WEINTRAUB et al., 1988).

Particularmente, nos animais não ruminantes, o tipo de gordura presente na dieta constitui a maior fonte de variação na composição em ácidos graxos dos lipídios de depósito (LUDKE \& LOPES, 1999). Portanto, adicionando-se ácidos graxos ômega 3 na dieta dos animais eles poderão ser incorporados nas carnes e os consumidores poderão contar com essas fontes de ácidos graxos como auxílio para preservação da saúde (TEIXEIRA, 2004). A suplementação de DHA para humanos aumenta gradativamente a sua concentração na membrana das células, entre elas dos eritrócitos, e após a suspensão da suplementação os níveis não retornam aos valores basais, o que pode proporcionar melhor resposta a problemas de saúde, principalmente relacionados ao coração (CAO et al., 2006).

Há convergência entre vários países para a relação PUFAS ômega 6 e 3 na dieta de humanos ficando essa entre 4 - 5:1 (MARTIN et al., 2006). Segundo Schmitz \& Ecker (2008) a exigência diária para PUFAS ômega 3 é de 350 a $400 \mathrm{mg}$. A essencialidade dos ácidos graxos de cadeia longa é muito dependente do metabolismo do indivíduo, sendo que a razão ômega 6/ômega 3 da dieta exerce grande influência nesse sentido (MARTIN et al., 2006).

Na Tabela 2 é mostrado o perfil de ácidos graxos em alimentos frescos de origem animal. 
NUNES, J.K. et al. Ácidos graxos poli-insaturados de cadeia longa na alimentação de não ruminantes. PUBVET, Londrina, V. 7, N. 12, Ed. 235, Art. 1552, Junho, 2013.

Tabela 2. Perfil de ácidos graxos em alimentos frescos de origem animal

\begin{tabular}{lccccccc}
\hline Ácido graxo & $\begin{array}{c}\text { Carne* } \\
\text { suína }\end{array}$ & $\begin{array}{c}\text { Carne* } \\
\text { bovina }\end{array}$ & $\begin{array}{c}\text { Carne* } \\
\text { de } \\
\text { frango }\end{array}$ & $\begin{array}{c}\text { Banha } \\
\text { suína }\end{array}$ & $\begin{array}{c}\text { Sebo } \\
\text { bovino }\end{array}$ & $\begin{array}{c}\text { Óleo } \\
\text { de } \\
\text { frango }\end{array}$ & $\begin{array}{c}\text { Óleo de } \\
\text { peixe** }\end{array}$ \\
\hline $\begin{array}{l}\text { Gordura (\%) } \\
\text { Ácidos }\end{array}$ & 26,5 & 23,5 & 15,1 & 100 & 100 & 99,8 & 100 \\
graxos (\% & & & & & & & \\
da gordura) & & & & & & & \\
$16: 0$ & 23,10 & 24,06 & 20,92 & 23,8 & 24,9 & 21,6 & 9,84 \\
$18: 0$ & 12,70 & 20,71 & 5,78 & 13,5 & 18,9 & 6,0 & 4,25 \\
$18: 1(n-9)$ & 43,00 & 32,27 & 34,33 & 41,2 & 36,0 & 37,3 & 16,98 \\
$18: 2(n-6)$ & 8,06 & 2,51 & 19,12 & 10,2 & 3,1 & 19,5 & 1,54 \\
$18: 3(n-3)$ & 0,60 & 0,72 & 0,93 & 1,0 & 0,6 & 1,0 & 1,06 \\
$20: 4(n-6)$ & 0,19 & 0 & 0,53 & 0 & 0 & 0,1 & 0,675 \\
$20: 5(n-3)$ & 0 & 0 & 0,07 & 0 & 0 & 0 & 13,02 \\
$22: 6(n-3)$ & 0 & 0 & 0,20 & 0 & 0 & 0 & 18,23 \\
\hline
\end{tabular}

*Carne mecanicamente separada, **Salmão.

Fonte: USDA (2008).

Os PUFAS ômega 6 são considerados geradores de eicosanoides próinflamatórios e os ômega 3 geradores de mediadores opostos destas vias, sendo considerados anti-inflamatórios. O DHA está presente em alta concentração no cérebro e na retina dos animais (TREVIZAN \& KESSLER, 2009).

As propriedades imunomoduladoras anti-inflamatórias dos PUFAS ômega 3 sugerem a sua utilização como substituto para os antibióticos. Os efeitos de promoção da saúde destes ácidos graxos poli-insaturados estão bem documentados em humanos (CALDER, 2006). Em aves, o consumo de dietas com derivados de peixe, ricas em ômega 3, particularmente ácido EPA e DHA, tem demonstrado melhorias no ganho de peso (PITA et al., 2006), redução na resposta inflamatória e alteração nos parâmetros imunes, incluindo produção de anticorpos, aumento na proporção de linfócitos e melhor capacidade de resposta (WANG et al., 2000). 


\section{Ômega 3 e 6 para suínos}

Na silagem de peixe, Ottati \& Bello (1990) relataram que 48,96\% da sua constituição é de ácidos graxos poli-insaturados, sendo o DHA em maior concentração $(22,16 \%)$. A adição de até $6,0 \%$ de silagem de subprodutos da filetagem de peixe na dieta de suínos em crescimento não afetou os parâmetros séricos - triglicerídeos, colesterol, total e lipoproteínas (VLDL, HDL e LDL) - avaliados mesmo tendo sido observado alterações nas concentrações da ureia plasmática (GODOY e al., 2008).

Ao adicionarem óleo de peixe a dieta de suínos, Irie \& Sakimoto (1992) observaram que a quantidade de ácidos graxos ômega 3 na gordura dos animais aumentou com redução da sua firmeza.

Morgan et al. (1992) ao adicionaram PUFAS ômega 3 na dieta de suínos observaram aumento significativo destes ácidos graxos na gordura da carcaça, sem verificarem efeitos adversos durante o tratamento da carcaça e modificação aguda nas características organolépticas durante o cozimento.

O uso de produtos de peixe, a fim de aumentar o teor de ácidos graxos poli-insaturados da série ômega 3 na carne e subprodutos, nas dietas dos animais deve ser com cautela, pois pode trazer problemas associados ao aroma e a maior susceptibilidade dos produtos cárnicos à oxidação (WOOD, 1999).

Os fosfolípidios, em muitas espécies, são os principais componentes lipídicos dos espermatozoides e caracterizam-se pela grande quantidade de ácidos graxos poli-insaturados. Em alguns mamíferos, o ácido docosahexanoico é o dominante, enquanto que em outras espécies é o ácido eicosapentanoico o principal componente da membrana espermática (OLIVEIRA et al., 2006). O sêmen suíno, por exemplo, apresenta, em grande quantidade, os ácidos graxos poli-insaturados (PENNY et al., 2000). A presença de alta concentração de ácidos graxos poli-insaturados dentro das frações lipídicas dos espermatozoides torna-os altamente susceptíveis à peroxidação, com consequente risco de danos à estrutura celular (NIKI et 
al., 1993). A relação dos ácidos graxos poli-insaturados das séries ômega 3 e 6 é importante para a manutenção das características espermáticas, uma vez que a fluidez e a flexibilidade da membrana dos espermatozoides é diretamente influenciada pela sua composição lipídica (STRZEZEK et al., 2004).

Na membrana plasmática dos espermatozoides o nível total de PUFAS diminui significativamente no sêmen congelado e descongelado quando comparado ao sêmen fresco, isto pode ocorrer em consequência do aumento relativo na proporção de gorduras saturadas, ou, devido à perda de ácidos graxos poli-insaturados (CEROLINI et al., 2001).

Moraes et al. (2010) usaram 3,5\% de óleo de soja ou de salmão e três níveis de antioxidantes - 150, 300 e $450 \mathrm{mg}$ de vitamina $\mathrm{E} / \mathrm{kg}$ - na dieta de suínos por 10 semanas, para avaliarem a qualidade do sêmen in natura. Os autores observaram que os espermatozoides dos animais tratados com óleo de salmão, por serem ricos em PUFAS e mais susceptíveis à peroxidação, apresentaram maior grau de peroxidação com consequente redução na concentração de antioxidantes. O volume, a motilidade espermática total, o teste hiposmótico, a percentagem de espermatozoides vivos e a morfologia espermática não diferiram entre os tratamentos. O óleo de salmão melhorou o vigor espermático.

Em suínos, a suplementação com óleo de peixe na dieta não demonstrou efeito significativo para motilidade, concentração, volume do ejaculado e percentagem de espermatozoides vivos quando comparada a dieta com milho moído (YESTE et al., 2011).

Comparando o conteúdo lipídico e a composição de ácidos graxos do ejaculado e do plasma seminal de suínos que expressaram motilidade espermática normal e baixa, Am-In et al. (2011) concluíram que as diferenças nos valores de motilidade espermática encontrados estão associados ao conteúdo de PUFAS ômega 3 presentes na membrana plasmática, pois os mesmos desempenham papel importante na motilidade, na viabilidade e na fluidez da membrana. Os autores sugeriram a 
suplementação de PUFAS ômega 3 na dieta ou a adição de substâncias antioxidantes no ejaculado, a fim de proteger a membrana plasmática da peroxidação lipídica.

\section{Ômega 3 e 6 para aves}

A composição de ácidos graxos da gordura abdominal, dos músculos do peito e da coxa de frangos de corte pode ser manipulada mediante mudança na composição de ácidos graxos da dieta (SCAIFE et al., 1994; HRDINKA et al., 1996).

Os PUFAS ômega 3 e 6 podem ser convertidos enzimaticamente em eicosanoides que atuam modulando a resposta inflamatória e imunológica; além disso, desempenham papel importante na agregação plaquetária, no crescimento e na diferenciação celular (CARMO \& CORREIA, 2009).

Também relacionada à síntese de eicosanoides, tem-se o crescimento e o desenvolvimento ósseo (GARCIA, 2009). O crescimento de um animal depende do desenvolvimento muscular e do suporte ósseo. Entretanto, nas linhagens modernas de frangos de corte, principalmente nos machos, a taxa de crescimento do tecido muscular é extremamente elevada e se inicia em uma fase muito precoce pós-eclosão, sobre um suporte esquelético frágil (GONZALES \& MENDONÇA JR., 2006). Dessa forma, a seleção genética para alta taxa de crescimento tem promovido maior peso do músculo do peito em comparação aos músculos e ossos das pernas, o que aumenta os problemas de pernas em frangos de corte (YALCIN et al., 2001).

Pesquisas têm comprovado que os lipídios da dieta são essenciais na biologia óssea, pois são capazes de influenciar a composição em ácidos graxos da membrana fosfolipídica e a atividade celular óssea (WATKINS et al., 2000; WATKINS, 2003). Essa influência parece estar relacionada à síntese de eicosanoides, principalmente prostaglandinas (GARCIA, 2009). De todos os eicosanoides produzidos, as prostaglandinas parecem ser as principais substâncias envolvidas na regulação local do metabolismo ósseo 
(WATKINS, 1992). Ainda neste sentido, Chang et al. (1998), citado por Fleming (2008) afirmam que as prostaglandinas derivadas dos PUFAS da série ômega 6 , em particular, a prostaglandina 2, demonstram ter alguns efeitos inibidores sobre o desenvolvimento ósseo, enquanto que a prostaglandina derivada dos PUFAS da série ômega 3 pode ter efeitos mais benéficos sobre os osteoblastos estimulando a formação e a função óssea.

Segundo Liu et al. (2003), os ácidos graxos poli-insaturados obtidos a partir de óleo de peixe melhoraram a resistência tibial de codornas (Coturnix japonica). McCormack et al. (2006), citado por Fleming (2008), demonstraram que a substituição de óleo de milho por óleo de salmão em pintinhos com 14 dias de idade melhorou as características ósseas, como força de cisalhamento e teor de cinzas.

Watkins et al. (2000) relatam que os lipídios fornecidos na alimentação podem afetar a composição dos ácidos graxos presentes nos fosfolipídios da membrana, influenciando a função da célula óssea.

Ao incluírem óleo de peixe em dietas semipurificadas para frangos de corte com oito semanas de idade, Xu et al. (1994) verificaram aumento na concentração de ácidos graxos poli-insaturados da série ômega 3 nos condrócitos e nas vesículas da matriz da cartilagem epifisária. Fleming (2008) afirma que o uso do óleo de salmão, produto rico em PUFAS ômega 3 e oriundo dos resíduos da indústria pesqueira, pode melhorar as características ósseas de frangos de corte, podendo ser facilmente incorporados às dietas avícolas.

\section{Ômega 3 e 6 para cães e gatos}

Devido a adição de óleos vegetais, as rações para cães e gatos contém uma proporção maior dos PUFAS ômega 6 em relação aos ômega 3 (HAND et al., 2000), assim sendo é possível inferir que a membrana da maioria das células apresentam maior quantidade de ácido araquidônico, derivado do ácido graxo ômega 6 , que é o principal precursor de eicosanoides pró- 
inflamatórios - prostaglandinas, tromboxanos e leucotrienos - que são os mais relacionados à carcinogênese (LARSSON et al., 2004).

Há evidências epidemiológicas que demonstram os efeitos da suplementação de PUFAS ômega 3 na prevenção e no tratamento de doenças crônicas, como as neoplasias, doenças cardiovasculares e resistência a insulina. No caso das neoplasias, os PUFAS ômega 3 atuam reduzindo a taxa de crescimento tumoral e metástase, pois agem como suporte nutritivo e modulador do sistema imunológico (RIEDIGER et al., 2009).

Os altos níveis de ácidos graxos poli-insaturados da série ômega 3, na dieta de cães, pelo uso de óleo de peixe, em relação a dietas baixas em ômega 3, determinaram um aumento de $219 \%$ no DHA e de $23 \%$ no ácido alfa-linolênico dos fosfolipídeos do plasma (DELT ON-VANDENBROUCKE et al., 1998).

Ao utilizar linhaça (alta teor de ácido linolênico) na dieta de cães, Rees et al. (2001) observaram nos fosfolipídeos do plasma aumento de $124 \%$ no EPA sem efeito sobre os níveis de DHA. Os cães que receberam dietas enriquecidas com óleo de peixe em comparação com cães que receberam dietas com óleo de milho mostraram níveis plasmáticos menores de ácido linoleico e araquidônico e aumento em nove vezes nos níveis totais de ácidos graxos ômega 3 (HALL et al., 2005). A dose dietética de PUFA ômega 3 é mais determinante para o nível plasmático destes ácidos graxos do que a relação ômega 6:ômega3 (HALL et al, 2006).

De acordo com o NRC (2006) as exigências nutricionais, em base seca, de EPA + DHA para cães em crescimento são menores que $0,05 \%$.

Culp et al. (1980) suplementaram a dieta de cães com $25 \%$ de óleo de peixe, durante 45 dias, e após induziram trombose e infarto com monitoramento dos animais por eletrocardiograma durante 19 horas. Nos cães controle a frequência dos batimentos cardíacos aumentou em $80 \%$ e nos cães que receberam o óleo de peixe o aumento foi menor que $30 \%$. Nestes animais, o tamanho do infarto no ventrículo esquerdo foi de $3 \%$ em 
NUNES, J.K. et al. Ácidos graxos poli-insaturados de cadeia longa na alimentação de não ruminantes. PUBVET, Londrina, V. 7, N. 12, Ed. 235, Art. 1552, Junho, 2013.

comparação com $25 \%$ nos animais do tratamento controle. Os autores sugeriram que a suplementação da dieta com óleo de peixe pode reduzir os danos do miocárdio associado com trombose das artérias coronárias.

A redução da produção de eicosanoides inflamatórios a partir de DHA e EPA é a justificativa da sua utilização em determinadas patologias inflamatórias, pois seus mecanismos de ação seriam similares ao de determinados anti-inflamatórios (ASTORG et al., 2004).

No tratamento do câncer, a suplementação da dieta com óleo de peixe tem sido associada com uma melhor recuperação e uma menor inflamação dos tecidos adjacentes, isso porque ocorre aumento da quantidade de ácidos graxos de cadeia longa nas membranas celulares, o que gera durante o tratamento do câncer peroxidação lipídica com formação de ácidos graxos mais reativos e isso potencializa a morte da célula tumoral. A dose recomendada para cães e gatos com câncer é $100 \mathrm{mg}$ para cada 5 a $10 \mathrm{~kg}$ de peso, uma vez ao dia, podendo ser obtida na forma de óleo de peixe (PIBOT et al., 2006).

\section{Considerações finais}

Pelos benefícios que proporciona aos animais não ruminantes e aos humanos que se alimentam com carne de aves e suínos a indústria de alimentos tende a investir na produção de alimentos funcionais que contenham EPA e/ou DHA.

\section{Referências}

AM-IN, N.; KIRKWOOD, R.N.; TECHAKUMPHU, M.; TANTASUPARUK, W. Lipid profiles of sperm and seminal plasma from boars having normal or low sperm motility. Theriogenology, v.75, p.897-903, 2011.

ANVISA - Agência Nacional de Vigilância Sanitária. Diretrizes Básicas para análise e comparação de propriedades funcionais. In: REGULAMENTO TÉCNICO. Brasília: Anvisa, resolução n.18, 1999.

ASTORG, P. Dietary n-6 e n-3 polyinsaturated fatty acids and prostate cancer risk: a review of epidemiological and experimental evidences. Cancer Causes and Control, v.15, p.367386, 2004. 
BERQUIN, I.M.; EDWARDS, I.J.; CHEN, Y.Q. Multi-targeted therapy of cancer by omega-3 faty acids. Cancer Lett, v.269, n.2, p.363-377, 1008.

CALDER, P.C. n-3 Polyunsaturated fatty acids, inflammation, and inflammatory diseases. The American of Journal of Clinical Nutrition, v.83, p.1505S-1519S, 2006.

CAO, J.; SCHWICHTENBERG, K.A.; HANSON, N.Q.; TSAI, M.Y. Incorporation and clearance of omega-3 fatty acids in erythrocyte membranes and plasma phospholipids. Clinical Chemistry, v.52, n.12, p.2265-2272, 2006.

CARMO, N.C.N.S., CORREIA, M.I.T.D.A importância dos ácidos graxos Ômega-3 no câncer. Revista Brasileira de Cancerologia, v55, n.3, p.279-287, 2009.

CEROLINI, S.; MALDJIAN, A.; PIZZI, F. et al. Changes in sperm quality and lipid composition during cryopreservation of boar semen. Reproduction, v.121, p.395-401, 2001.

CHANG, D.J.; JI, C.; KIM, K.K.; CASINGHINO, S.; McCARTHY, T.L.; CENTRELLA, M. Reduction in transforming growth factor beta receptor 1 expression and transcription factor CBFa1 on bone cells by glucocorticoid. Journal of Biological Chemistry, v.273, p.48924896, 1998.

CONIGLIO, J.G. How does fish oil lower plasma triglycerides? Nutrition Reviews, v.50, n.7, p.195-206, 1992.

CULP, B.R.; LANDS, W.E.M.; LUCCHESI, B.R.; PITT, B.; ROMSON, J. The effect of dietary supplementation of fish oil on experimental myocardial infarction. Prostaglandins, v.20, p.1021-1031, 1980.

DELT ON-VANDENBROUCKE, I.; MAUDE, M.B.; CHEN, H.; AGUIRRE, G.D.; ACLAND, G.M.; ANDERSON, R.E. Effect of diet on the fatty acid and molecular species composition of dog retina phospholipids. Lipids, v.33, n.12 p.1187-1193, 1998.

GARCIA, E. R. M.; MURAKAMI, A. E.; MATSUSHITA, M.; DALALIO, M.M.O.; DELLA-ROSA, V.A.; FERNANDES, J.I.M. Efeito da inclusão de óleo de linhaça sobre a composição lipídica e a concentração de prostaglandina (PGE2) em ossos longos de frangos de corte. Revista Brasileira de Zootecnia. v.38, n.7, p.1247-1255, 2009

GODOY, H.B.R. de; LANDEL FILHO, L.C.; SOBRINHO, E.B.; GODOY, M.M. de. O uso da silagem de subprodutos da filetagem de peixe na alimentação de suínos em crescimento parâmetros séricos. Brazilian Journal of Veterinary Rearch and Animal Science, v.45, n.6, p.429-436, 2008.

GONZALES, E.; MENDONÇA JR., C.X. Problemas locomotores em frangos de corte. In: SIMPÓSIO BRASIL SUL DE AVICULTURA, 7., 2006, Chapecó. Anais... Chapecó: Embrapa Suínos e Aves, 2006. p.79-94.

HALL, J.A.; HENRY, L.R.; JHA, S. Dietary (n-3) fatty acids alter plasma fatty acids and leukotriene $B$ synthesis by stimulated neutrophils from healthy geriatric Beagles. Prostaglandins, Leukotrienes and Essential Fatty Acids, v.73, p.335-341, 2005.

HALL, J.A.; PICTON, R.A.; SKINNER, M.M. The (n-3) Fatty Acid dose, independent of the (n$6)$ to $(n-3)$ fatty acid ratio, affects the plasma fatty acid profile of normal dogs. Journal Nutrition, v.136, p.2338-2344, 2006. 
HAND, M.S.; THATCHER, C.D.; REMILLARD, R.L. Small animal clinical nutrition. 4.ed. Marceline: Walsworth Publishing, 2000.

HRDINKA, C.; ZOLLITSCH, W.; KNAUS, W. et al. Effects of dietary fatty acids pattern on melting point and composition of adipose tissues and intramuscular fat of broiler carcasses. Poultry Science, v.75, p.208-215,1996.

IRIE, M., SAKIMOTO, M. Fat characteristics of pigs fed fish oil containing eicosapentaenoic and docosahexaenoic acids. Journal of Animal Science, v.70, p.470-477, 1992.

LARSSON, S.C.; KUMLIN, M.; SUNDBERG, M.; WOLK, A. Dietary long-chain n-3 fatty acids for th prevention of câncer: a review of potential mechanisms. American Journal of Clinical Nutrition, v.79, p.935, 2004.

LIU D, VEIT HP, WILSON JH \& DENBOW DM. Longterm supplementation of various dietary lipids alters bone mineral content, mechanical properties and histological characteristics of Japanese quail. Poultry Science, v.82, p.463-473, 2003.

LUDKE, M.C.M.M.; LÓPEZ, J. Colesterol e composição dos ácidos graxos nas dietas para humanos e na carcaça suína. Ciência Rural, v.29, n.1, p.81-87, 1999.

MCCORMACK, H.A.; FLEMING, R.H.; MCTIER, L.; WHITEHEAD, C.C. Influence of dietary fatty acid $n-3 / n-6$ balance on bone characteristics in young broilers. British Poultry Abstract, v.3, p.25-26, 2006.

MORAES, E.A.; TORRES, C.A.A.; GUIMARÃES, J.D.; MURGAS, L.D.S. Efeito de fontes de óleo e níveis de suplementação de vitamina $E$ na ração sobre as características físicas e morfológicas do sêmen in natura de suínos. Arquivo Brasileiro de Medicina Veterinária e Zootecnia, v.62, n.3, p.521-527, 2010.

MOURÃO, D.M.; MANTEIRO, J.B.R.; COSTA, N.M.B.; STRINGHETA, P.C.; MINIM, V.P.R.; DIAS, C.M.G.C. Ácido linoléico conjugado e perda de peso. Revista de Nutriçãos, v.18, n.3, p.391-399, 2005.

MORGAN, C.A.; NOBLE, R.C.; COCCHI, M.; McCARTNEY, R. Manipulaion of the fatty acid composition of pig meat lipids by dietary means. Journal Science Food Agriculture, v.58, p.357-368, 1992.

MORRIS, J.G. Do cats need arachidonic acid in the diet for reproduction? Journal of Animal Physiology and Animal Nutrition, v.88, p.131-137, 2004.

NIKI, E.; NOGUCHI, N.; GOTOH, N. Dynamics of lipid peroxidation and its inhibition by antioxidants. Biochemal Society Transactions, v.21, p.313-317, 1993.

NRC - NATIONAL RESEARCH COUNCIL. Nutrient requirements of dogs and cats. Washington, D.C.: National Academies Press, 2006.

NORUM, K.R. Dietary fat and blood lipids. Nutrition Reviews, v.50, n.4, p.30-37, 1992.

OLIVEIRA, S.L.; FIALHO, E.T.; MURGAS, L.D.S.; FREITAS, J.A. de; FREITAS, R.T.F.; ZANGERONIMO, M.G. Efeito da inclusão de diferentes tipos de óleo na dieta de varrões sobre a qualidade do sêmen in natura. Ciência e Agrotecnologia, v.30, n.6, p.1205-1210, 2006.

OTTATI, G.M.; BELLO, R.A. Ensilado microbiano de pescado em la alimentacion porcina. 1. Valor nutritivo del producto em dietas para cerdos. Alimentaria, v.211, p.37-44, 1990. 
PENNY, P.C.; NOBLE, R.C.; MALDJIAN, A.; CEROLINI, S. Potencial role of lipids for the enhancement of boar fertility and fecundity. Pig News and Information, v.25, p.119-126, 2000 .

PIBOT, P.; BIORGE, V.; ELLIOTTI, D. Enciclopedia de la nutrición clinica canina. 4 ed. França: Aniwa, 2006.

PITA, M.C.G.; PIBER NETO, E.; CARVALHO, P.R.; MENDONÇA JÚNIOR, C.X. Efeito da suplementação de linhaça, óleo de canola e vitamina E na dieta sobre as concentrações de ácidos graxos poliinsaturados em ovos de galinha. Arquivo Brasileiro de Medicina Veterinária e Zootecnia, v.58, n.5, p.925-931, 2006.

RAMOS, S.; RAMOS, M.E.M. Dieta e risco cardiovascular: ômega 3, óleo de oliva, oleaginosas, o que é fato?. Revista da Sociedade de Cardiologia do Rio Grande do Sul, ano 14, n.6, p.10-12, 2005.

REES, C.A.; BAUER, J.E.; BURKHOLDER, W.J.; KENNIS, R.A.; DUNBAR, B.L.; BIGLEY, K.E. Effects of dietary flaxseed and sunflower seed supplementation on normal canine serum unsaturated fatty acids and skin and hair coat condition scores. Veterinary Dermatology, v.12, p.111-117, 2001.

RIEDIGER, N.D.; OTHMAN, R.A.; SUH, M.; MOGHADASIAN, M.H.A. Systemic review of the roles of n-3 fatty acids in heath and disease. Journal of American Dietetic Association, v.109, p.668-679, 2009.

SCAIFE, J.R.; MOYO, J.; GALBRAITH, H. et al. Effect o different dietary supplemental fats and oils on the tissue fatty acid composition and growth of female broilers. British Poultry Science, v.35, p.107-118, 1994.

SCHMITZ, G.; ECKER, J. The opposing effects of $n-3$ and $n-6$ fatty acids. Progress in Lipid Research, v.47, p.147-155, 2008.

SILVA, G.J.C. Colesterol: O mito do colesterol e doenças coronarianas em poedeiras e no homem. Avicultura Ciência \& Tecnologia, ano 3, n.15, p.2-4, 1995.

STRZEŻEK, J.; FRASER, L.; KUKLIŃSKA, M.; DZIEKONSKA, A.; LECEWICZ, M. Effects of dietary supplementation with polyunsaturated fatty acids and antioxidants on biochemical characteristics of boar semen. Reproductive Biology, v.4, n.3, p.271-287, 2004.

TEIXEIRA, A.S. 2004. O que é PUFA Omega-3? Disponível em: <http://www.ovosenriquecidos.com.br>. Acesso em: 04 de dezembro de 2012.

TREVIZAN, L.; KESSLER, A.M. Lipídeos na nutrição de cães e gatos: metabolismo, fontes e uso em dietas práticas e terapêuticas. Revista Brasileira de Zootecnia, v.38, p.15-25, 2009.

USDA - U. S. Department of Agriculture, Agricultural Research Service. 2008. National Nutrient Database for Standard Reference, Release 21. Nutrient Data Laboratory Home Page, Disponível em: <http://www.ars.usda.gov/ba/bhnrc/ndl> Acesso em: 29 de novembro de 2012.

WANG, Y.W.; FIELD, C.J.; SIM, J.S. Dietary polyunsaturated fatty acids alter lymphocyte subset proportion and proliferation, serum immunoglobulin $\mathrm{G}$ concentration, and immune tissue development in chicks. Poultry Science, v.79, p.1741-1748, 2000. 
WATKINS, B.A. Factors involved in the local regulation of bone biology. In: WHITEHEAD, C.C. Bone biology and skeletal disorders in poultry. England: Carfax Publishing Company, p.67-86.1992.

WATKINS, B.A.; LI, Y.; ALLEN, K.G.D. et al. Dietary ratio of $(n-6) /(n-3)$ polyunsaturated fatty acids alters the fatty acid composition of bone compartments and biomarkers of bone formation in rats. Journal of Nutrition, v.130, n.9, p.2274-2284, 2000.

WATKINS, B.A.; LI, Y.; LIPPMAN, H.E. et al. Modulatory effect of omega-3 polyunsaturated fatty acids on osteoblast function and bone metabolism. Prostaglandins, Leukotrienes and Essential Fatty Acids, v.68, p.387-398, 2003.

WEINTRAUB, M.S.; ZECHNER, R.; BROWN, A.; EISENBERG, S.; BRESLOW, J. Dietary polyunsaturated fats of the $W$ - and $W-3$ series reduce postprandial lipoprotein levels. Chronic and acute effects of fat saturation on postprandial lipoprotein metabolism. Journal Clinical Invest, v.82, p.1884-1893, 1988.

WOOD, J.D.; EUSER, M.; FISCHER, A.V.; MITE, G.R.; RICHARDSON, R.I.; SHEARD, P.R. Manipulating meat quality and composition. In: PROCEEDINGS OF THE NUTRITION SOCIETY, 58, 1999, Anais..., 1999. p.363.

XU, H.; WATKINS, B.A.; ADKISSON, H.D. Dietary lipids modify the fatty acid composition of cartilage, isolated chondrocytes and matrix vesicles. Lipids, v.29, n.9, p.619-625, 1994.

YALCIN, S.; ÖZKAN, S.; COSKUNER, E. et al. Effects of strain, maternal age and sex on morphological characteristics and composition of tibial bone in broilers. British Poultry Science, v.42, n.2, p.184-190, 2001.

YESTE, M.; BARRERA, X.; COLL, D.; BONET, S. The effects on boar sperm quality of dietary supplementation with omega-3 polyunsaturated fatty acids differ among porcine breeds. Theriogenology, v.76, p.184-196, 2011. 